\title{
HUBUNGAN SISTEM PEMBUANGAN LIMBAH RUMAH TANGGA DAN KONTRUKSI SUMUR GALI DENGAN KUALITAS FISIK AIR DI WILAYAH KERJA PUSKESMAS SALO
}

\author{
Ade Dita Puteri \\ S1 Kesehatan Masyarakat Universitas Pahlawan Tuanku Tambusai \\ adedita10@gmail.com
}

\begin{abstract}
According to data from WHO ((World Health Organization) every person in developed countries needs between 60-120 liters of water per day. Dug wells meet health requirements including in Indonesia. Dug wells provide water from a layer of soil that is relatively close to the surface of the soil. Therefore, dug wells are easily contaminated through seepage. The aim of this study was to determine the relationship between household sewage systems and construction. dug wells with physical water requirements in the working area of the Salo Health Center in 2020. The design used in this study is descriptive analytic with a cross sectional approach. Random sampling is 91 houses, and the data analysis used is univariate $t$ and bivariate. The results of the bivariate analysis show that there is a significant relationship between the household waste disposal system and the physical requirements of water in the work area of the Salo Health Center in 2020 with a $p$ value of 0.003, there is a significant relationship between dug well construction and the physical requirements of water in the work area of the Salo Health Center in 2020 with the p. value 0.001. The community should always monitor and improve the physical conditions that allow it to be fixed so that the infiltration of waste water does not enter the dug wells and the quality of dug well water is maintained.
\end{abstract}

Keywords $\quad$ : Dug Well Construction, Household Waste Disposal System, Physical Water Requirements

\begin{abstract}
ABSTRAK
Menurut data $W H O$ ((World Health Organization) setiap orang di negara-negara maju memerlukan air antara 60-120 liter per hari. Sumur gali menyediakan air yang berasal dari lapisan tanah yang relatif dekat dari permukaan tanah. Oleh karena itu, sumur gali sangat mudah terkontaminasi melalui rembesan. Tujuan penelitian ini adalah untuk mengetahui hubungan hubungan sistem pembuangan limbah rumah tangga dan kontruksi sumur gali dengan kualitas fisik air di wilayah kerja Puskesmas Salo . Desain yang digunakan pada penelitian ini deskriptif analitik dengan pendekatan cross sectional. Populasi dalam penelitian ini adalah seluruh rumah yang memiliki sumur gali yang berada di wilayah kerja Puskesmas Salomenggunakan metode simple random sampling yaitu sebanyak 91 rumah. Analisa data yang digunakan adalah univariat dan bivariat. Hasil analisa bivariat diketahui ada hubungan yang signifikan antara sistem pembuangan limbah rumah dengan kualitas fisik air di wilayah kerja Puskesmas Salodengan p value 0,003, ada hubungan yang signifikan antara kontruksi sumur gali dengan kualitas fisik air di wilayah kerja Puskesmas Salodengan p value 0,001. Bagi masyarakat hendaknya selalu memantau dan memperbaiki kondisi fisik yang memungkinkan untuk dibenahi agar peresapan air limbah tidak masuk ke dalam sumur gali dan kualitas air sumur gali tetap terjaga.
\end{abstract}

Kata Kunci : Kontruksi Sumur Gali, Sistem Pembuangan Limbah Rumah Tangga, Kualitas Fisik Air

\section{PENDAHULUAN}

Air merupakan kebutuhan dasar bagi kehidupan, khususnya bagi manusia yang selama hidupnya selalu memerlukan air. Tubuh manusia sebagian besar terdiri dari air. Pada tubuh orang dewasa, sekitar 55-60 $\%$ berat badan terdiri dari air, anak-anak sekitar 65\%, dan untuk bayi sekitar $80 \%$. Menurut WHO, tiap orang di negara-negara maju memerlukan air antara 60-120 liter per hari, sedangkan di negara-negara 
berkembang, termasuk Indonesia, tiap orang memerlukan air antara 30-60 liter per hari. Air digunakan oleh manusia untuk keperluan sehari-hari seperti minum, mandi, cuci, kakus, dan sebagainya. Diantara kegunaan-kegunaan air tersebut, yang sangat penting adalah kebutuhan untuk minum. Oleh karena itu, untuk keperluan minum, termasuk untuk masak, air harus mempunyai perkualitasan khusus agar tidak menimbulkan penyakit pada manusia (Soemirat, 2009)

Air yang secara terus-menerus mengalami proses daur ulang memberi peluang bagi manusia untuk dapat memanfaatkan 3 jenis sumber air di bumi yaitu air hujan, air tanah, dan air permukaan. Dari tiga jenis sumber air tersebut air tanah dan air permukaan yang paling banyak digunakan sebagai sumber air minum, mandi, dan mencuci seharihari, baik di desa maupun di perkotaan. Hal ini dapat dipahami karena air tanah dan air permukaan keberadaanya mudah didapat. Pada hakikatnya manusia berupaya mengadakan air yang cukup bagi dirinya. Namun dalam banyak hal, air yang digunakan tidak selalu sesuai dengan kualitas kesehatan karena sering ditemukan air tersebut mengandung bibit penyakit ataupun zat-zat tertentu yang dapat menimbulkan penyakit dan justru membahayakan kelangsungan hidup manusia. Hal ini disebabkan oleh karena banyaknya pencemaran yang terjadi pada air, terutama air tanah (Azwar, 2006).

Sifat air yang merupakan pelarut yang baik menyebabkan air di alam tidak pernah murni akan tetapi selalu mengandung berbagai zat terlarut maupun zat tidak terlarut serta mengandung mikroorganisme atau jasad renik. Air yang terganggu kualitasnya ini dikatakan sebagai air yang tercemar. Apabila air telah tercemar maka kehidupan manusia akan terganggu. Hal ini merupakan bencana besar sebab tanpa air tidak ada kehidupan di muka bumi ini (Wardhana, 2007).

Air yang dipergunakan oleh masyarakat untuk keperluan sehari-hari tersebut masih banyak yang belum memenuhi perkualitasan kesehatan. Oleh karena itu, pengelolaan sumber daya air sangat penting agar dapat dimanfaatkan secara berkelanjutan sesuai dengan tingkat mutu yang diinginkan. Salah satu langkah pengelolaan yang dilakukan adalah pemantauan dan interpretasi data kualitas air mencakup kualitas fisik, kimia, dan biologi (Effendi, 2006).

Dampak dari pencemaran air bersih maupun air minum dapat menimbulkan kerugian yang lebih jauh lagi, yaitu kematian. Kematian dapat terjadi karena pencemaran yang terlalu parah sehingga air itu sendiri telah menjadi penyebab berbagai macam penyakit. Namun banyak penduduk terpaksa memanfaatkan air yang kurang bagus kualitasnya. Tentu saja hal ini akan berakibat kurang baik bagi kesehatan masyarakat. Dalam jangka pendek, kualitas air yang kurang baik dapat mengakibatkan muntaber, diare, kolera, tipus, atau disentri. Hal ini dapat terjadi pada keadaan sanitasi lingkungan yang kurang baik. Bila air tanah dan air permukaan tercemari oleh kotoran, secara otomatis kuman-kuman tersebar ke sumber air yang dipakai untuk keperluan rumah tangga. Dalam jangka panjang, air yang berkualitas kurang dapat mengakibatkan penyakit keropos tulang, korosi gigi, anemia, dan kerusakan ginjal. Hal ini terjadi karena terdapat logam-logam berat yang banyak bersifat toksik (racun) di dalam air dan pengendapan pada ginjal (Kusnaedi, 2008).

Kualitas fisik air bersih maupun air minum yang ideal seharusnya jernih, tidak berwarna, tidak berasa, dan tidak berbau, serta tidak mengandung bakteri patogen maupun zat-zat yang membahayakan bagi kesehatan manusia. Untuk mencegah terjadinya penularan penyakit yang semakin meningkat oleh karena air, ada hal penting yang perlu diperhatikan yaitu pemantauan kualitas air secara periodik serta konstruksi dari sarana penyediaan air bersih Elfianora (2009).

Sumur gali adalah satu konstruksi sumur yang paling umum dan meluas 
dipergunakan untuk mengambil air tanah bagi masyarakat kecil dan rumah-rumah perorangan sebagai air minum. Sekitar $45 \%$ masyarakat di Indonesia menggunakan sumur sebagai sarana air bersih, dan dari $45 \%$ yang menggunakan sarana sumur tersebut, diperkirakan sekitar $75 \%$ menggunakan jenis sumur gali (Chandra, 2007).

Sumur gali menyediakan air yang berasal dari lapisan tanah yang relatif dekat dari permukaan tanah. Oleh karena itu, sumur gali sangat mudah terkontaminasi melalui rembesan. Umumnya rembesan berasal dari tempat buangan kotoran manusia dan hewan juga dari limbah sumur itu sendiri, baik karena lantainya maupun saluran air limbahnya yang tidak kedap air. Keadaan konstruksi dan cara pengambilan air sumur pun dapat merupakan sumber kontaminasi. Misalnya sumur dengan konstruksi terbuka dan pengambilan air dengan timba. Sumur dianggap mempunyai tingkat perlindungan sanitasi yang baik bila tidak terdapat kontak langsung antara manusia dengan air di dalam sumur (Entjang, 2000).

Limbah rumah tangga adalah limbah yang berasal dari dapur, kamar mandi, cucian, limbah bekas industri rumah tangga dan kotoran manusia. Limbah merupakan buangan atau sesuatu yang tidak terpakai berbentuk cair, gas dan padat. Dalam air limbah terdapat bahan kimia yang sukar untuk berbahaya. Bahan kimia tersebut dapat memberi kehidupan bagi kumankuman penyebab penyakit disentri, tipus, kolera dan penyakit lainnya. Air limbah harus diolah agar tidak mencemari dan tidak membahayakan kesehatan lingkungan. Air limbah harus dikelola untuk mengurangi pencemaran. (Depkes RI, 2012).

Keberadaan sumur gali (SGL) baik dari segi konstruksinya maupun jarak peletakan terhadap sumber pencemaran masih sangat memprihatinkan disebabkan karena adanya konstruksi SGL yang tidak memenuhi kualitas kesehatan dan letaknya kurang diperhatikan, sehingga mempunyai resiko tinggi terjadinya pencemaran kualitas air baik yang berasal dari jamban, sampah dan dari air buangan lainnya. (Depkes RI, 2012).

Kostruksi sumur gali sebagian besar tidak memenuhi kualitas didukung dengan hasil penelitian tentang jarak sumur dari sumber pencemaran dominan memenuhi kualitas $(73,3 \%)$ yakni minimal 10 meter, bibir sumur dominan memenuhi kualitas $(60,0 \%)$ yakni tinggi $\geq 1$ meter, dinding sumur dominan memenuhi kualitas $(73,3$ $\%)$ dengan tinggi bibir sumur $\geq 3$ meter. Kedalaman sumur gali berbeda-beda. Hal ini terjadi karena keberadaan air dalam tanah yang tidak sama di setiap daerah. Bentuk sumur gali pada umumnya berbentuk bundar dengan garis tengah sekitar 80-100 cm. (Soemirat, 2010).

Tabel 1 Laporan Sarana Air Bersih dan Air Minum Puskesmas Salo.

\begin{tabular}{|c|c|c|c|c|c|c|c|c|c|c|}
\hline No & $\begin{array}{c}\text { Desa/ } \\
\text { Kelurahan }\end{array}$ & $\begin{array}{l}\text { Jumlah } \\
\text { Rumah }\end{array}$ & SGL & $\%$ & Ledeng & $\%$ & $\overline{\text { SPT }}$ & $\%$ & $\mathbf{P A}$ & $\%$ \\
\hline 1 & Salo & 3283 & 661 & 20 & 819 & 24 & 201 & 6 & 27 & 0,8 \\
\hline 2 & Siabu & 3274 & 752 & 22 & 1032 & 31 & 73 & 2 & 0 & 0 \\
\hline 3 & Salo Timur & 976 & 543 & 55 & 383 & 39 & 76 & 7 & 0 & 0 \\
\hline 4 & Sipungguk & 690 & 554 & 80 & 351 & 50 & 77 & 11 & 0 & 0 \\
\hline 5 & $\begin{array}{l}\text { Ganting } \\
\text { Damai }\end{array}$ & 731 & 653 & 80 & 462 & 50 & 74 & 10 & 0 & 0 \\
\hline 6 & Ganting & 776 & 543 & 55 & 383 & 39 & 76 & 7 & 0 & 0 \\
\hline & Jumlah & 9730 & 3706 & 30 & 3430 & 31 & 577 & 5 & 27 & 0,8 \\
\hline
\end{tabular}


Berdasarkan Laporan Tahunan Puskesmas Salo, di dapatkan bahwa penduduk yang memakai sarana sumur gali adalah sebanyak 3706 rumah dari 9730 rumah yang ada di Wilayah Kerja Puskesmas Salo.

Berdasarkan latar belakang diatas, maka peneliti melakukan penelitian dengan judul" hubungan sistem pembuangan limbah rumah tangga dan kontruksi sumur gali dengan kualitas fisik air sumur gali di Wilayah Kerja Puskesmas Salo"

\section{METODE}

Penelitian ini bersifat deskriptif analitik dengan menggunakan pendekatan potong lintang (cross sectional) untuk melihat hubungan antara sisitem pembuangan limbah rumah tangga dan kontruksi air sumur gali (SGL) dengan kualitas fisik air sumur gali di Wilayah Kerja Puskesmas Salo . Penelitian ini dilakukan pada bulan Desember tahun 2020 di Wilayah Kerja Puskesmas Salo yang meliputi 6 Wilayah yaitu : Salo, Siabu, Sipungguk, Ganting, Ganting Damai dan Salo Timur. Sampel dalam penelitian ini adalah masyarakat yang berada di wilayah kerja Puskesmas Salo yang menurut perhitungan jumlah sampel berjumlah 91 Sampel yang dapat memenuhi kriteria penelitian. Teknik pengambilan sampel dalam penelitian ini adalah accidental sampling.

\section{HASIL}

Bab ini menyajikan mengenai hasil penelitian tentang hubungan sistem pembuangan limbah rumah tangga dan kontruksi sumur gali dengan kualitas fisik air sumur gali di Wilayah Kerja Puskesmas Salo . Penelitian ini dilakukan pada tanggal 22 November sampai 04 Desember tahun 2020 dengan jumlah responden 91 orang. Untuk lebih jelasnya dapat dilihat dalam bentuk analisis univariat danbivariat

\section{Analisa Univariat}

\section{Sistem Pembuangan Limbah Rumah Tangga \\ Tabel 2 Distribusi Frekuensi Berdasarkan Sistem Pembuangan Limbah Rumah Tangga di Wilayah Kerja Puskesmas Salo}

\begin{tabular}{llcc}
\hline No & $\begin{array}{l}\text { Sistem Pembuangan } \\
\text { Limbah Rumah } \\
\text { Tangga }\end{array}$ & F & $\mathbf{( \% )}$ \\
\hline 1 & $\begin{array}{l}\text { Tidak memenuhi } \\
\text { Kualitas }\end{array}$ & 57 & 62,6 \\
\hline 2 & Memenuhi Kualitas & 34 & 37,4 \\
\hline Jumlah & $\mathbf{9 1}$ & $\mathbf{1 0 0}$ \\
\hline
\end{tabular}

Dari tabel 2 dapat dilihat bahwa sistem pembuangan limbah rumah tangga responden sebagian besar tidak memenuhi kualitas yaitu sebanyak 57 unit $(62,6 \%)$.

\section{Kontruksi Sumur Gali \\ Tabel 3 Distribusi Frekuensi Berdasarkan Kontruksi Sumur Gali di Wilayah Kerja Puskesmas Salo}

\begin{tabular}{llcc}
\hline No & Kontruksi sumur gali & F & $\mathbf{( \% )}$ \\
\hline 1 & $\begin{array}{l}\text { Tidak memenuhi } \\
\text { Kualitas }\end{array}$ & 61 & $\mathbf{6 7 , 0}$ \\
\hline 2 & Memenuhi Kualitas & 30 & 33,0 \\
\hline Jumlah & $\mathbf{9 1}$ & $\mathbf{1 0 0}$ \\
\hline
\end{tabular}

Dari tabel 3 dapat dilihat bahwa kontruksi sumur gali sebagian besar tidak memenuhi kualitas yaitu sebanyak 61 unit $(67,0 \%)$.

\section{Kualitas Fisik Air Sumur Gali \\ Tabel 4 Distribusi Frekuensi Berdasarkan Kualitas fisik Air di Wilayah Kerja Puskesmas Salo}

\begin{tabular}{llcl}
\hline No & Kualitas fisik air & F & $\mathbf{( \% )}$ \\
\hline 1 & $\begin{array}{l}\text { Tidak memenuhi } \\
\text { kualitas }\end{array}$ & 52 & 57,1 \\
\hline 2 & Memenuhi kualitas & 39 & 42,9 \\
\hline Jumlah & $\mathbf{9 1}$ & $\mathbf{1 0 0}$ \\
\hline
\end{tabular}

Dari tabel 4 dapat dilihat bahwa kualitas fisik air sebagian besar tidak memenuhi kualitas yaitu sebanyak 58 unit $(63,7 \%)$. 


\section{Analisa Bivariat}

Analisa bivariat ini memberi gambaran hubungan sistem pembuangan limbah rumah tangga dan kontruksi sumur gali dengan kualitas fisik air sumur gali di Wilayah Kerja Puskesmas Salo . Sehingga hasil analisis disajikan pada tabel berikut:

Hubungan Sistem pembuangan limbah rumah tangga dengan kualitas fisik air sumur gali di Wilayah Kerja Puskesmas Salo

Tabel 5 Distribusi Kualitas Fisik Air Sumur Gali Menurut Sistem Pembuangan Limbah Rumah Tangga di Wilayah Kerja Puskesmas Salo

\begin{tabular}{|c|c|c|c|c|c|}
\hline \multirow{3}{*}{$\begin{array}{l}\text { Sistem Pembuangan } \\
\text { Limbah Rumah } \\
\text { Tangga }\end{array}$} & \multicolumn{2}{|c|}{ Kualitas Fisik Air } & \multirow[b]{2}{*}{ Total } & \multirow{3}{*}{$\begin{array}{c}\text { RP } \\
\text { C1 95\% }\end{array}$} & \multirow[b]{2}{*}{ P Value } \\
\hline & $\begin{array}{c}\text { Tidak Memenuhi } \\
\text { Kualitas }\end{array}$ & $\begin{array}{l}\text { Memenuh } \\
\text { i kualitas }\end{array}$ & & & \\
\hline & $\mathrm{N}$ & $\mathrm{N}$ & $\mathrm{N}$ & & \multirow{5}{*}{0,001} \\
\hline Tidak memenuhi & $36(73,5 \%)$ & $13(26,5 \%)$ & $49(100 \%)$ & \multirow{4}{*}{$\begin{array}{c}1,93 \\
(1,27- \\
2,94\end{array}$} & \\
\hline kualitas & & & & & \\
\hline Memenuhi kualitas & $16(38,1 \%)$ & $26(61,9 \%)$ & $42(100 \%)$ & & \\
\hline Jumlah & $52(57,1 \%)$ & $39(42,9 \%)$ & $91(100 \%)$ & & \\
\hline
\end{tabular}

$X^{2}=10 \overline{156}$

Berdasarkan tabel 5 dapat dilihat bahwa dari 49 sistem pembuangan limbah rumah tangga responden yang tidak memenuhi kualitas terdapat $36(73,5 \%)$ yang memiliki kualitas fisik air yang tidak memenuhi kualitas. Dari uji statistik ada hubungan antara sistem pembuangan limbah rumah tangga dengan kualitas fisik air sumur gali di wilayah kerja Puskesmas Salo(p value
0,001), Rasio Prevalens 1,93 (95\% CI 1,272,94), Sistem pembuangan limbah rumah tangga yang tidak memenuhi kualitas beresiko kualitas fisik air sumur galinya tidak memenuhi kualitas 1,93 kali lebih besar dibandingkan sistem pembuangan limbah rumah tangga yang memenuhi kualitas.

\section{Hubungan Konstruksi Sumur Gali dengan Kualitas Fisik Air Sumur Gali di Wilayah Kerja Puskesmas Salo}

Tabel 6 Distribusi Kualitas Fisik Air Sumur Gali Menurut Kontruksi Sumur Gali di Wilayah Kerja Puskesmas Salo

\begin{tabular}{|c|c|c|c|c|c|}
\hline \multirow[b]{2}{*}{$\begin{array}{l}\text { Kontruksi } \\
\text { Sumur Gali }\end{array}$} & \multicolumn{2}{|c|}{ Kualitas Fisik Air } & \multirow[t]{2}{*}{ Total } & \multirow{2}{*}{$\begin{array}{c}\text { RP } \\
\text { C1 95\% }\end{array}$} & \multirow[t]{2}{*}{$P$ value } \\
\hline & $\begin{array}{c}\text { Tidak memenuhi } \\
\text { kualitas } \\
\mathbf{N} \\
\end{array}$ & $\begin{array}{c}\text { Memenuh } \\
\text { i kualitas } \\
\mathbf{N}\end{array}$ & & & \\
\hline $\begin{array}{l}\text { Tidak memenuhi } \\
\text { kualitas }\end{array}$ & $42(68,9 \%)$ & $19(31,1 \%)$ & $61(100 \%)$ & $2.07(1.21-$ & 0007 \\
\hline $\begin{array}{l}\text { Memenuhi } \\
\text { kualitas }\end{array}$ & $10(33,3 \%)$ & $20(66,7 \%)$ & $30(100 \%)$ & $3,52)$ & \\
\hline Jumlah & $52(57,1 \%)$ & $39(42,9 \%)$ & $91(100 \%)$ & & \\
\hline
\end{tabular}

Berdasarkan tabel 6 dapat dilihat bahwa dari 61 kontruksi sumur gali responden yang tidak memenuhi kualitas terdapat 42 $(68,9 \%)$ yang memiliki kualitas fisik air yang tidak memenuhi kualitas. Dari uji statistik ada hubungan antara sistem pembuangan limbah rumah tangga dengan kualitas fisik air sumur gali di wilayah kerja Puskesmas Salo (p value 0,007), Rasio Prevalens 2,07 (95\% CI 1,21-3,52), 
kontruksi sumur gali yang tidak memenuhi kualitas beresiko kualitas fisik air sumur galinya tidak memenuhi kualitas 2,07 kali lebih besar dibandingkan kontruksi sumur gali yang memenuhi kualitas.

\section{PEMBAHASAN}

\section{Hubungan Sistem pembuangan limbah} rumah tangga dengan Kualitas Fisik Air

Dari hasil penelitian dapat diketahui bahwa terdapat hubungan sistem pembuangan rumah tangga dengan kualitas fisik air sumur gali dibuktikan dengan $p$ value $=0,003$

Limbah rumah tangga adalah limbah yang berasal dari dapur, kamar mandi, cucian, limbah bekas industri rumah tangga dan kotoran manusia. Limbah merupakan buangan atau sesuatu yang tidak terpakai berbentuk cair, gas dan padat. Dalam air limbah terdapat bahan kimia yang sukar untuk dihilangkan dan berbahaya. Bahan kimia tersebut dapat memberi kehidupan bagi kuman-kuman penyebab penyakit disentri, tipus, kolera dan penyakit lainnya. Air limbah tersebut harus diolah agar tidak mencemari dan tidak membahayakan kesehatan lingkungan (Suratno, 2010)

Menurut peneliti sistem pembuangan air limbah rumah tangga yang tidak memenuhi kualitas dapat mempengaruhi kualitas fisik air sumur gali karena dalam air limbah terdapat bahan kimia yang sukar untuk dihilangkan dan berbahaya. Bahan kimia tersebut dapat memberi kehidupan bagi kuman-kuman penyebab penyakit disentri, tipus, kolera dan penyakit lainnya.

Hasil penelitian ini sesuai dengan penetian yang dilakukan oleh Surahmi (2011) di Kecamatan Pancur batu yang menyatakan bahwa sistem pembuangan limbah rumah tangga mempengaruhi kualitas fisik air. Begitu juga dengan penelitian yang dilakukan Suparman \& Iwan (2015) dalam penelitian yang dilakukannya di Desa Beleka kecamatan Praya Timur Kabupaten Lombok Tengah yang menyatakan bahwa ada ubungan yang siginifikan antara kualitas saluran pembuangan air limbah (SPAL) dengan kualitas fisik air sumur gali.

Hasil tersebut juga didukung oleh hasil penelitian Hartini (2012) yang menyatakan bahwa ada hubungan yang signifikan antara kondisi saluran pembunagan air limbah dengan kualitas fisik air sumur gali

\section{Hubungan Kontruksi Sumur Gali dengan Kualitas Fisik Air}

Dari hasil penelitian dapat diketahui bahwa terdapat hubungan kontruksi sumur gali dengan kualitas fisik air sumur gali dibuktikan dengan $\mathrm{p}$ value $=0,001$, Sumur gali adalah satu konstruksi sumur yang paling umum dan meluas dipergunakan untuk mengambil air tanah bagi masyarakat kecil dan rumah-rumah perorangan. Konstruksi sumur gali yang baik dapat mengurangi atau bahkan menghindarkan dari pencemaran yang disebabkan oleh limbah domestik maupun bakteri. Pada umumnya pencemaran berasal dari tempat buangan kotoran manusia kakus/jamban, juga dari limbah sumur itu sendiri baik dari lantainya maupun saluran air limbahnya yang tidak kedap air. Keadaan konstruksi sumur gali pun dapat merupakan sumber kontaminasi terhadap air sumur gali. Bisa saja sumur yang lebih dekat dengan sumber pencemar lebih baik kualitasnya di bandingkan sumur yang lebih jauh dari sumber pencemar yang dalam hal ini di karenakan oleh konstruksi dari sumur gali tersebut. Dari segi kesehatan sebenarnya penggunaan sumur gali ini kurang baik bila cara pembuatannya tidak benar-benar diperhatikan, tetapi untuk memperkecil kemungkinan terjadinya pencemaran dapat diupayakan pencegahannya (Santoso, 2009).

Berdasarkan hasil penelitian diketahui sebanyak $83,33 \%$ sample sumur gali tidak memenuhi kualitas dinding sumur yakni minimal $3 \mathrm{~m}, 56,66 \%$ sample sumur gali tidak memenuhi kualitas bibir sumur yang baik yakni minimal $70 \mathrm{~cm}, 81,67 \%$ dari sample sumur gali tidak memenuhi kualitas lantai sumur yang baik dengan minimal 1,5 $\mathrm{m}$ di sekeliling sumur gali, 91,67\% dari 
sampel sumur gali tidak memenuhi kualitas jarak antara sumur gali terhadap septic tank yang baik dengan minimal $10 \mathrm{~m}$ dan sebanyak $90 \%$ dari sampel sumur gali memiliki jarak 1-2 $\mathrm{m}$ antara sumur gali terhadap saluran pembuangan limbah. Banyaknya kondisi sumur gali yang tidak memenuhi kualitas mengakibatkan besarnya kemungkinan pencemaran air yang terjadi pada sumur gali. Kerentanan ini akan mengakibatkan kualitas air yang di hasilkan baik kualitas fisik, kimia ataupun bakteriologis semakin buruk.

Menurut peneliti konstruksi sumur gali yang tidak memenuhi kualitas dikarenakan banyak faktor diantaranya adalah sedikitnya faktor pengetahuan terhadap dampak konstruksi sumur gali yang tidak memenuhi kualitas yang dimiliki oleh pemiliki sumur. Selain faktor pengetahuan, faktor lain yang mempengaruhi konstruksi sumur tidak memenuhi kualitas adalah keadaan perekonomian penduduk di Kecamatan Salo yang menggunakan sumur gali sebagai sumber air dimana untuk membuat sumur dengan konstruksi sumur yang memenuhi kualitas membutuhkan dana yang cukup.

Hasil penelitian ini sesuai dengan penelitian Dahari (2009) Pengaruh Kontruksi Air Sumur Gali dengan Kualitas fisik Air di Kecamatan Biringkanaya Kota Makassar". Diperoleh hasil bahwa kontruksi sumur gali yang tidak memenuhi kualitas mempengaruhi kualitas fisik air dengan $p$ value 0,001 .

Hasil penelitian ini juga didukung oleh hasil penelitian Wijaya (2012). Setelah diuji secara statistic diperoleh p-value 0,03 $<0,05$ berarti ada hubungan yang signifikan anatar kondisi sumur dan kondisi saluran pembuangan air limbah dengan kualitas fisik air sumur.

Hasil penelitian yang dilakukan oleh Mangarey dkk (2015) menyatakan hal yang sama bahwa terdapat hubungan antara konstruksi sumur gali dengan kualitas total coliform air sumur gali dengan nilai $\mathrm{p}$ value 0,003. Penelitian dari Akbar (2015) dengan judul gambaran kondisi fisik sumur gali dan kualitas bakteriologis air sumur gali, menunjukkan hasil bahwa salah satu hal yang mempengaruhi tingginya total coliform pada sumur gali adalah jika konstruksi sumur tidak memenuhi kualitas. Kondisi fisik sumur gali seperti tidak di semen dapat menyebabkan pencemaran, sebab air sumur gali dapat tercemar lewat rembesan yang masuk melalui pori - pori tanah. Adanya penutup sumur pada sumur gali dapat berfungsi untuk meminimalisir resiko pencemaran terhadap sumur gali. Keberadaan lantai sumur juga penting, yaitu lantai sumur harus terbuat dari semen dan lebarnya $\geq 1 \mathrm{~m}$ ke seluruh arah yang melingkari sumur dengan kemiringan 10 derajat ke arah tempat pembuangan air (Chandra 2007). Semakin baik konstruksi dari sumur gali tersebut maka kandungan bakteri coliform akan semakin sedikit.

\section{KESIMPULAN}

Setelah dilakukan penelitian tentang tentang hubungan sistem pembuangan limbah rumah tangga dan kontruksi sumur gali dengan kualitas fisik air sumur gali di Wilayah Kerja Puskesmas Salo maka dapat diambil kesimpulan, Sebagian besar kualitas fisik air sumur gali di Wilayah Kerja Puskesmas Salo tidak memenuhi kualita, Sebagian besar sistem pembuangan limbah rumah tangga di Wilayah Kerja Puskesmas Salotidak memenuhi kualitas. Sebagian besar kontruksi sumur gali di Wilayah Kerja Puskesmas Salo tidak memenuhi kualitas. Terdapat hubungan sistem pembuangan limbah rumah tangga dengan kualitas fisik air sumur gali di Wilayah Kerja Puskesmas Salo. Terdapat hubungan kontruksi sumur gali dengan kualitas fisik air sumur gali di Wilayah Kerja Puskesmas Salo

\section{UCAPAN TERIMAKASIH}

Ucapan terimakasih disampaikan kepada yang telah membantu dalam proses penelitian serta semua pihak yang 
telah memberikan banyak bantuan dalam menyelesaikan penelitian ini.

\section{DAFTAR PUSTAKA}

Abah. (2010), Kesehatan Lingkungan. Diperoleh dari htp//kesehatanlingkungan.co.id pada tanggal 5 Mei 2020

Azwar (2005). Telaah Kualitas Air Bagi Pengelolaan Sumber Daya dan Lingkungan Perairan. Yogyakarta:Kanisius

Chandra. (2007). Penyediaan Air Bersih $(P A B)$. Jurusan Kesehatan Lingkungan FKM Universitas Hasanuddin Makassar.

Depkes RI. (2012). Konsep metode Standar Pemeriksaan Fisik, Kimia, Dan Radioaktifitas Air, Departemen Kesehatan Republik Indonesia, Jakarta.

- (2011). Konsep metode Standar Pemeriksaan Fisik, Kimia, Dan Radioaktifitas Air, Departemen Kesehatan Republik Indonesia, Jakarta.

Entjang, (2000). Karakteristik Air Sumur Gali Di Kelurahan Lerekang Kecamatan Labakkang Kabupaten Pangkep Tahun 2000, Skripsi STIK Tamalatea Makassar.

Machfoedz.( 2004). Telaah Kualitas Air Bagi Pengelolaan Sumber Daya dan Lingkungan Perairan. Kanisius. Yogyakarta.

Suryana. (2013). Studi Kualitas Air Berdasarkan Konstruksi Sumur Gali (SGL) di Wilayah Kerja Puskesmas Antang Kota Makassar. Jurusan Kesehatan Lingkungan. Makassar.

KemenKes, RI. (2011). Pedoman Penentuan Status Mutu Air Dengan Metode Indeks Pencemaran. Deputi MENLH. Jakarta.

Cahya. (2012). Pencemaran Air dan Pemanfaatan Limbah Industri. Rajawali. Jakarta.
Nursalam. (2003). Konsep dan Penerapan Metodologi Penelitian Ilmu Keperawatan. Pedoman dan Skripsi, Tesis dan Instrumen Penelitian Keperawatan. Edisi kedua. Jakarta: Salemba Medika

Hidayat. (2007). Metode Penelitian Keperawatan \& Teknik Analisis Data. Jakarta : Salemba Medika

Permenkes. (1990). Standar kualitas air bersih.diperoleh pada tanggal 15 Mei 2020

Puteri, A. D. (2017). Analisis faktor yang berhubungan dengan kondisi rumah sehat di desa bandur picak kecamatan koto kampar hulu tahun 2017. Prepotif J Kesehat Masy, 1(2), 28-41

Sastrawijaya, A.T. 2009. Pencemaran Lingkungan. Penerbit Rineka Cipta.

Soemirat. (2010). Kesehatan Lingkungan, Gadjahmada University Press, Yogyakarta.

Syamsi. (2010). Dasar-Dasar Pengelolaan Air Limbah, Universitas Indonesia Press, Jakarta.

Suryana. (2013). Pengelolahan air bersih. Jakarta: Rhineka Cipt

Viona. (2013), Faktor yang Berhubungan dengan Kadar Merkuri pada Air Sumur Gali di Area Penambangan Emas Tanpa Izin di Desa SelogiriKabupaten Wonogiri Propinsi Jawa Tengah, Tesis, UNDIP, Semarang. 